\title{
Zinc-incorporated Microporous Molecular Sieve for Mild Catalytic Hydrolysis of Gamma-valerolactone: A New Selective Route for Biomass Conversion
}

\author{
Wei-Che Lin, Lin Ye, Simson Wu, Ben Lo, Yung-Kang Peng, Pu Zhao, Ian McPherson, Shik Chi Edman Tsang*
}

\begin{abstract}
Gamma-valerolactone (GVL) is regarded as a key platform molecule in the production of fine chemicals such as pentenoic acid (PA) from biomass. Although PA is believed to be the key intermediate in solid acid catalyzed reactions of GVL, due to subsequent facile decarboxylation reactions, further alkene products were formed. Here, by tailoring the acidity of Brønsted acid sites in an alumino-phosphate (AIPO) molecular sieve via incorporation of $\mathrm{Zn}^{2+}$ into the framework, we access a new selective and effective catalyst for GVL conversion to PA.
\end{abstract}

Chemicals derived from oil and gas constitute a large proportion of man-made chemicals in use today, ranging from liquid fuels to platform chemicals used in the synthesis of various products. ${ }^{[1]}$ However, there are increasing concerns about the depletion of these non-renewable resources and the associated issues of carbon accumulation in our atmosphere. Hence there is an urgent need to develop sustainable and preferably clean routes to chemical feedstocks. Biomass (such as sugars and lignocellulose) is an abundant natural resource on Earth, which has long been regarded as the potential alternative to mitigate these problems. ${ }^{[2]}$ The present low oil price as opposed to the high cost of bio-processing of biomass does not offer immediate economic incentives but vigorous activities in preparing the technologies are currently sought. ${ }^{[3]}$ Typically GVL, easily derived from the biomass, ${ }^{[4]}$ is generally regarded as the key green platform molecule to many valuable products. $^{[5]}$ It can be directly used as solvent ${ }^{[6]}$ or fuel additive ${ }^{[7]}$ It has also been shown that hydrolysis of the lactone group of GVL $(\mathrm{O}-\mathrm{C}=\mathrm{O})$ is facile, giving rise to various useful products. Mild acid hydrolysis of GVL to pentenoic acid (PA), would be a new green synthetic route from biomass since PA is widely used for fragrance, perfume, cosmetic, pharmaceuticals and plasticizer industries. Recently, Dumesic et al. have demonstrated the two stage catalytic conversion of GVL to hydrocarbon fuels. ${ }^{[8]}$ In this process, GVL molecule is believed to undergo acid-catalysed ring opening of GVL to produce PA, followed by an immediately decarboxylation over $\mathrm{SiO}_{2} / \mathrm{Al}_{2} \mathrm{O}_{3}$ to produce a gas stream of butene isomers and $\mathrm{CO}_{2}$. This stream is then passed over Amberlyst to achieve acid-catalysed oligomerization of butenes yielding higher alkenes with molecular weights suitable for gasoline and jet fuel applications. $^{[8]}$ Ye et al. have also shown that using Zn-doped H-ZSM-5, butene formed from GVL (via PA) over its acid site can rapidly undergo aromatisation to give benzene, toluene, xylene (BTX) products. ${ }^{[9]}$ The high yield production of PA itself, however, has not yet been demonstrated as the use of

Wei-Che Lin ${ }^{\dagger}$, Dr Lin Ye', Simson Wu, Dr Ben Lo, Dr Yung-Kang Peng, Dr Pu Zhao, Dr lan McPherson, Prof. Shik Chi Edman Tsang

Wolfson Catalysis Centre, Department of Chemistry, University of Oxford, Oxford, OX1 3QR, UK

† equal contribution co-first author; * E-mail: edman.tsang@chem.ox.ac.uk

Supporting information for this article is given via a link at the end. such acidic catalysts will lead to extremely rapid subsequent decarboxylation to hydrocarbons/aromatics.

Typical Brønsted acidic sites (BAS) from $\mathrm{SiO}_{2} / \mathrm{Al}_{2} \mathrm{O}_{3}$ or zeolites such as H-ZSM-5 contain small quantities of trivalent $\mathrm{Al}$ atoms incorporated into the silicate matrix. These sites are tetrahedrally surrounded by $\mathrm{O}$ atoms, thus the $\mathrm{O}$ atoms bonding to $\mathrm{Si}$ and $\mathrm{Al}$ are negatively charged. Charge balance is achieved by capturing a proton to generate $\mathrm{Al}-\mathrm{O}\left(\mathrm{H}^{+}\right)-\mathrm{Si}^{[10]}$ In order to develop milder BAS at high concentrations for the direct synthesis of PA from GVL without the subsequent acidcatalysed decarboxylation, tuning the acidity of non aluminosilicate support could be an interesting approach. Related to the zeolites are the alumino-phosphate molecular sieves, AlPOs. ${ }^{[11]}$ In these compounds the constructing atoms ( $\mathrm{T}$ atoms) are alternating $\mathrm{Al}$ and $\mathrm{P}$ atoms connected by $\mathrm{O}$ atoms, resulting in a neutrally charged lattice. Part of the T atoms can also be substituted by other elements. Here, we have employed the modification of AlPO with $\mathrm{Zn}^{2+}$ to introduce ( $\mathrm{Zn} / \mathrm{Al}$ ) $\mathrm{O}\left(\mathrm{H}^{+}\right)-\mathrm{P}$ acidic moieties. With this approach it is found that hydrolysis can be tuned to provide a high selectivity and yield towards PA product without the sequential decarboxylation reaction to hydrocarbons. This is in contrast with the immobilised $\mathrm{Zn}^{2+}$ extra framework species of H-ZSM-5 which produce aromatics/hydrocarbons from the GVL hydrolysis. ${ }^{[9]}$ Lately, breakthrough innovations have been made for the preparation of the single atom subsituted and immobilised catalyst. ${ }^{[12]}$ Such investigations can be facilitated by the use of porous supports with highly uniform structures, such as crystalline zeolites. ${ }^{[13]}$ Zeolites offer surface sites with uniformities that are unattainable on high-area oxide surfaces, which are inherently heterogeneous. ${ }^{[14]}$ For example, Gates et al. have claimed the direct imaging of single $\mathrm{La}$ and $\mathrm{Au}$ atom in zeolite HY. ${ }^{[15]}$ The confirmation of atomic dispersion on supports is mainly derived from recent advancements in aberration corrected scanning transmission electron microscopy, X-ray absorption techniques and modelling studies. However, detailed structural characterization of the immobilised atomic species by more accurate diffraction techniques has not been widely adopted due to a lack of sensitivity and extensive Bragg diffraction units of immobilised molecular species perpendicular to the disordered support surface. Recently, we have shown that using next generation synchrotron X-ray powder diffraction combined with Rietveld refinement, a slight but significant alteration in scattering parameters of the crystalline zeolite support framework atoms modified by surface organic or inorganic adsorbate enable the elucidation of the structure, geometries and interactions in zeolites in terms of atomic distances and angles, within experimental error. ${ }^{[16]}$

In this study, using probe molecule-synchrotron X-ray powder diffraction, combined with Rietveld refinement and probe molecule-NMR, we demonstrate that the AlPO framework-substituted $\mathrm{Zn}^{2+}$ environment is responsible for the introduction of mild acid sites able to hydrolyse GVL to PA. In contrast, we show that extra-framework immobilization of 
$\mathrm{Zn}^{2+}$ with terminal $\mathrm{Zn}-\mathrm{OH}$ into $\mathrm{H}-\mathrm{ZSM}-5$ will lead to nucleophilic decarboxylation of GVL to produce hydrocarbons/aromatics.

The catalytic testing results shown in Figure 1 suggest that by passing GVL in $\mathrm{N}_{2}$ over 4 different zeolite-based catalysts: AlPO-5, Zn-AlPO-5, H-ZSM-5 and Zn-ZSM-5 (see preparations in SI) under comparable conditions can give very different hydrolytic products. As seen from the figure, the main products over AlPO-5 catalysts are indeed the desirable PA and isomers. Although unmodified AlPO-5 gives 64\% selectivity towards the formation of PA with little activity for decarboxylation (8\%), only 1-2\% GVL conversion is achieved, indicating that this material is essentially not active for the GVL conversion. The conversion rises dramatically to $65 \%$ and the selectivity toward PA reaches $70 \%$ for Zn-AlPO-5, with the decarboxylation activity to $\mathrm{CO}_{2}$ further dropping to ca. $4 \%$. It is thus clear that the incorporation of $\mathrm{Zn}^{2+}$ into the AlPO-5 structure can somehow greatly promote the activity and selectivity for this hydrolysis reaction. It is interesting to note that under the same testing conditions, the catalytic performances of H-ZSM-5 based catalysts, give almost complete GVL conversion within the $24 \mathrm{~h}$ reaction time studied (Figure 1). For undoped H-ZSM-5, 85\% conversion was achieved, the total aromatics (benzene, toluene, xylene (BTX) and higher alkylaromatics selectivity is about $40 \%$ with the light alkanes/alkenes selectivity reaching $38 \%$, and only about $10 \%$ selectivity toward PA and $12 \%$ to $\mathrm{CO}_{2}$. This generally agrees with literature that demonstrate that strong BAS promote ring opening and decarboxylation to form butene and then aromatization to BTX product in ZSM-5. ${ }^{[17]}$ The addition of Sn, $\mathrm{Ga}$ and $\mathrm{Zn}$ can significantly increase the aromatics selectivity at the expense of light alkanes/alkenes, presumably due to the introduction of other active sites through these metal ions doping. ${ }^{[9]}$ Amongst the screened samples, Zn-ZSM-5 gives $96 \%$ of GVL conversion, the aromatics/hydrocarbons selectivity of $80 \%$ which is about $20 \%$ to $\mathrm{CO}_{2}$. The major gas phase product was found to be 1-butene (4.8\%, see SI). Evaluations of both Zn-AlPO-5 and Zn-ZSM-5 catalysts showed high catalytic activity, good lifetime and recyclability, making them promising candidates in future bio-processing. Particularly, ZnAlPO-5 gives higher yield toward PA, which may be developed as a new catalytic route for its green production from biomass.

However, there are a number of fundamental questions that remain to be answered: why does $\mathrm{Zn}^{2+}$ modification to AlPO-5 and H-ZSM-5 give completely different product distributions, with the former greatly suppressing acid-catalysed decarboxylation and the latter promoting the reaction? How does the structure and catalytic mechanism of the decarboxylation reaction by the two $\mathrm{Zn}$ containing microporous materials differ from each other?

It is noted that the structure of zeolite catalysts and their mechanistic pathways cannot be easily visualised through single crystal structure determination. However, the structure and the substrate-active site interaction in the zeolite, if known, could provide important hints to the catalytic activity. As a result, synchrotron X-ray powder diffraction (SXRD) combined with Rietveld refinement was used to monitor the coordination environment of Zn-AlPO-5 in comparison to that of Zn-ZSM-5. The $\mathrm{Zn}$ environment should reflect the nature of the interaction between $\mathrm{Zn}$ and GVL molecule during GVL hydrolysis over the two Zn-containing catalysts. Rietveld refinement was performed by TOPAS-5 (see analytical details in SI). As stated in experimental details in SI, more than 300 independent hkl reflections were used for the refinement, which allowed for a large number of structural variables to be refined in satisfactory manner. The quality of the Rietveld refinement was confirmed by well-fitted refinement profile, low R-weighted pattern (Rwp) values and goodness-of-fit (Figure 2(a) and Tables S4).

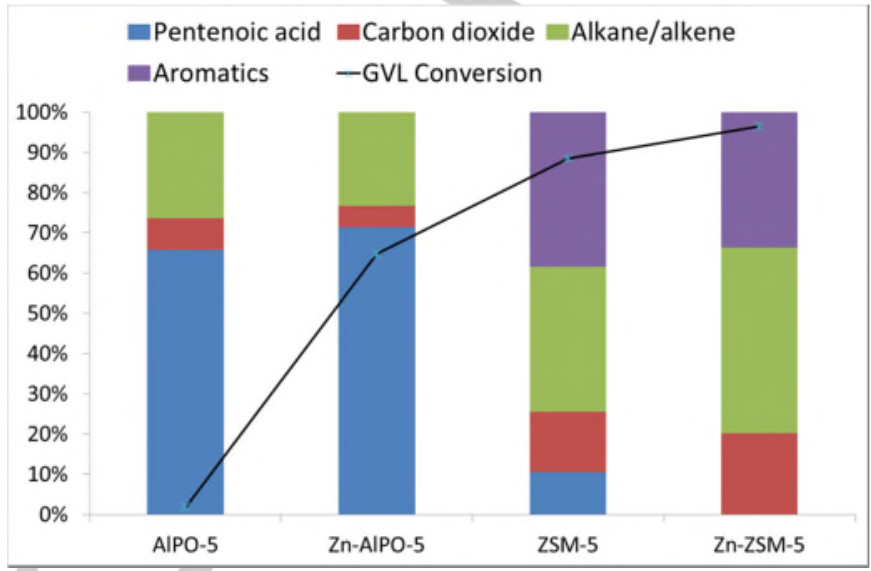

Figure 1. GVL catalytic results after 24 hours reaction for ( $\mathrm{Zn}$-)AlPO-5 and (Zn-)ZSM-5. 40wt\% GVL/water solution with flow rate $0.016 \mathrm{ml} / \mathrm{min}$ was pumped into a fixed bed stainless steel reactor that hosted $0.5 \mathrm{~g}$ of the catalysts sandwiched by quartz wool plugs. The carrier gas was $\mathrm{N}_{2}$ with a feed rate of $3 \mathrm{ml} \mathrm{min}^{-1}$ at reaction conditions of $397{ }^{\circ} \mathrm{C}$ and $10 \mathrm{bar}$.

In the refinement results, electron rich regions due to $\mathrm{NH}_{3}$ were clearly identified on the internal surface of the cross channels region of $\mathrm{Zn}$-AlPO-5 (Figure 2b). According to the crystallographic model shown in Figure $2 b$, there are two different kinds of $\mathrm{NH}_{3}$ positions observed inside the 6-member ring and 12-member ring regions (named as: N1(yellow) and $\mathrm{N} 2$ (green)). The $\mathrm{N} 2$ ammonia (green) is 3.06(2) $\AA$ away from the framework $\mathrm{O}$ and is in a 12-member ring. The other one $\mathrm{N} 1$ ammonia (yellow), however, is significantly closer to the framework O, with around 2.13(3) $\AA$. N1 ammonia is in a much narrow pore, which is a 6-member ring.

For comparison, in H-ZSM-5 the closest N-O (framework) of 3.49(2) $\AA$ was attributed to the Brønsted acid base $\mathrm{NH}_{4}{ }^{+}$like adduct of $(\mathrm{O}-\mathrm{H} \cdots \mathrm{N})$ was found in H-ZSM-5. ${ }^{[16 b]}$ The strength of the Brønsted acidity can be inferred from the $\mathrm{O}-\mathrm{H} \cdots \mathrm{N}$ distance. In fact, the lone pair on $\mathrm{N}$ of ammonia can be considered as a Brønsted base bonding to the proton of the BAS, forming an $\mathrm{NH}_{4}{ }^{+}$species. The distance between the $\mathrm{O}$ atom of BAS and the $\mathrm{N}$ atom of absorbed $\mathrm{NH}_{3}$ will therefore reflect the strength of the acidity. That is, the longer distance indicates the stronger acid strength of the $\mathrm{H}$ since the lengthening of $\mathrm{O}-\mathrm{N}_{\mathrm{NH} 4}{ }^{+}$implies a lower degree of $\sigma_{\mathrm{O}-\mathrm{H}}$ orbital overlap with the terminal $\mathrm{H}$ from the framework $\mathrm{O}$ compared to ammonia, giving higher extent of protonated ammonium. ${ }^{[16 b]}$ Accordingly, the distances of the $\mathrm{N}-\mathrm{O}$ in $\mathrm{Zn}$ AlPO-5 are 3.06(2) and 2.13(3) A, respectively as compared to $3.486(17) \AA$ in H-ZSM-5. This result suggests that the Brønsted acidity is much weaker in Zn-AlPO-5 than that of the H-ZSM5. 


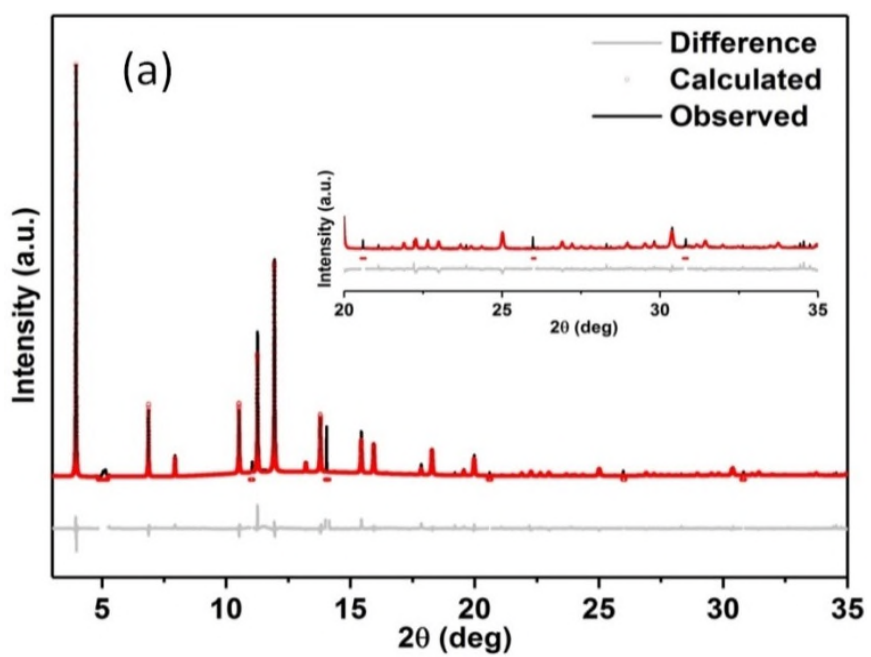

(b)

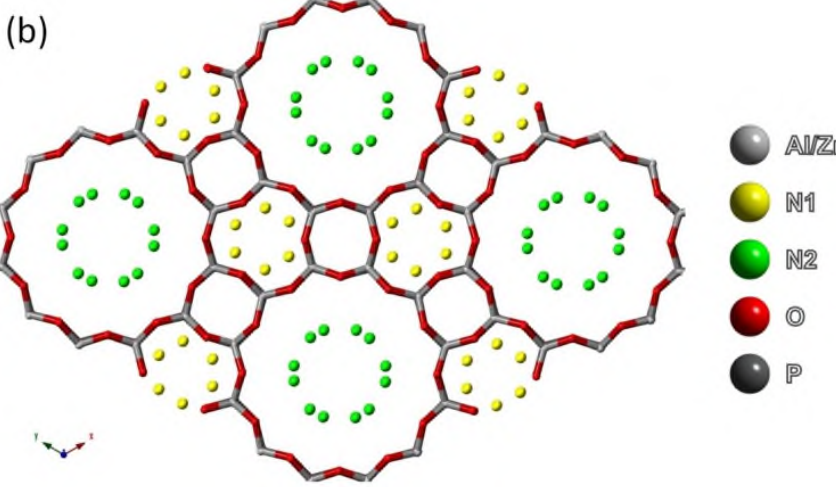

Figure 2. Fitted SXRD data and the structure detail of ammonia adsorbed Zn-AlPO-5 at room temperature. a, Comparison of the experiment data (black circle) and calculated data (red line) and the difference between them (grey line). b, The refined structure of ammonia adsorbed Zn-AlPO-5 at room temperature (viewed from b-axis). The framework of Zn-AlPO-5 is shown in the stick mode, red stick is $\mathrm{O}$ and grey stick is Si. The N1 and N2 types of ammonia molecules are highlighted in green balls and yellow balls, respectively, the former in 6-member ring while the latter in 10-member ring

Extended X-ray absorption fine structure (EXAFS) analysis shown in Figure 3 and Table 1 indicate the different zinc environment in Zn-AlPO-5 and in Zn-ZSM-5. According to the fitting results, zinc in Zn-AlPO-5 appears to coordinate with 4 oxygen atoms and the average $\mathrm{Zn}-\mathrm{O}$ distance is about $1.94 \AA$. This result indeed suggests that the zinc ion is isomorphically substituted on a $\mathrm{T}$ site in the framework. In contrast, it is interesting to note that the (average) coordination number of zinc ions in Zn-ZSM-5 is 5 instead of 4 . As seen from the refined structure shown in figure $\mathrm{S} 7$, two extra-framework $\mathrm{Zn}^{2+}$ species were observed, one is immobilized by surface oxygens to form terminal $\mathrm{Zn}-\mathrm{OH}$ as a 4 coordinate complex in the crosschannel region and the other one is 6 coordinate $\mathrm{Zn}^{2+}\left(\mathrm{H}_{2} \mathrm{O}\right)_{6}$ entrapped in the straight channel (Figure S7). As seen from Table 1, the derived $\mathrm{Zn}-\mathrm{O}$ distances and their coordination numbers from EXAFS for Zn-AlPO-5 and Zn-ZSM-5 are significantly different from each other.
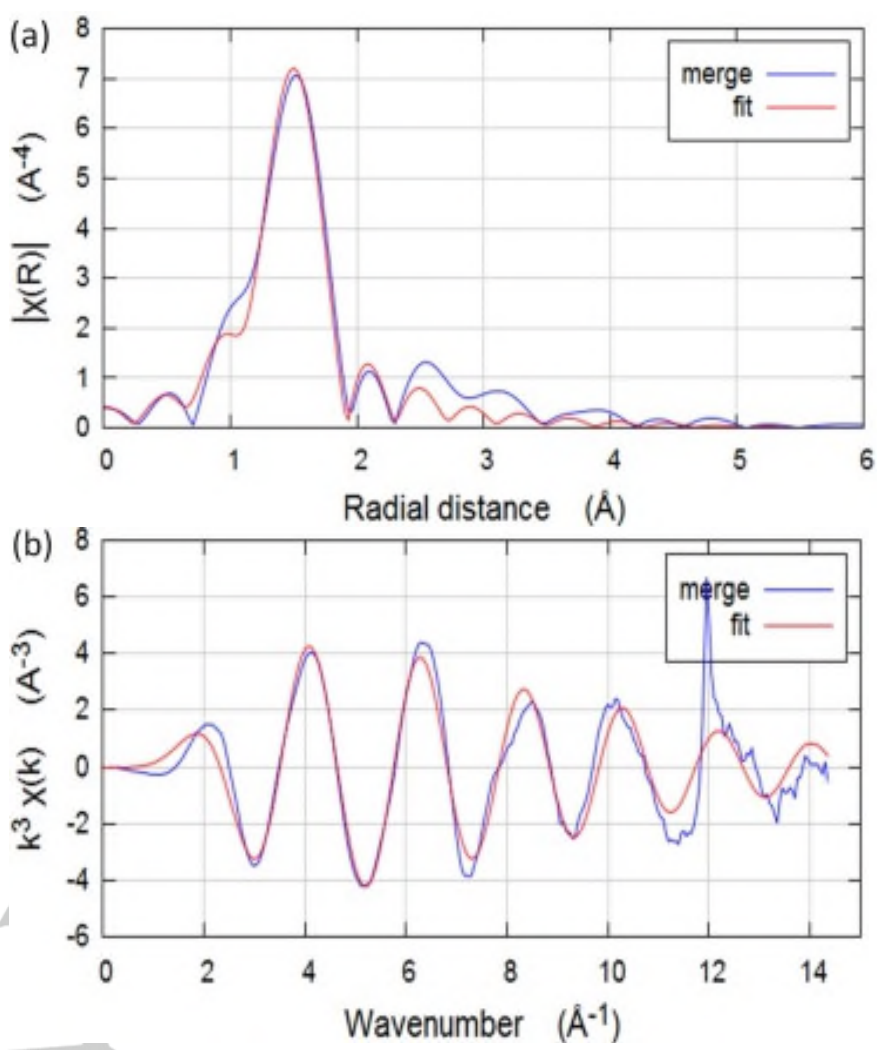

Figure 3. a, The best fitted EXAFS data of Zn-AlPO-5. The measured spectra are plotted in blue and the simulated spectra are plotted in red. b, The corresponding $\mathrm{k}^{3}$-weighted experimental and the simulated data

Table 1. Refined structural models from best fitted EXAFS data

\begin{tabular}{cccccc}
\hline Catalyst & & $\mathrm{CN}^{\text {EXAFS }}$ & $\mathbf{R}^{\text {EXAFS }}(\AA)$ & $\begin{array}{c}\text { Debye-Waller } \\
\text { factor }(\AA)\end{array}$ & $E_{\text {not }}(\mathrm{eV})$ \\
\hline Zn-AIPO-5 & Zn-O & $3.9(2)$ & $1.94(1)$ & $0.005(1)$ & 0.4 \\
Zn-ZSM-5 & Zn-O & $5.0(1)$ & $2.06(1)$ & $0.009(1)$ & 4.6 \\
\hline
\end{tabular}

Statistical errors are in brackets; $\mathrm{CN}$ stands for coordination number; $\mathrm{R}$ represents derived atomic distance (see SI).

In order to gain further information related to the BAS in the catalysts, all catalysts were analyzed by conventional $\mathrm{NH}_{3}$ temperature-programmed desorption (TPD), as shown in S8. According to the two peak positions and intensities for $\mathrm{NH}_{3}$ desorption from $\mathrm{Zn}-\mathrm{ZSM}-5$, the $\mathrm{NH}_{3}$ can be weakly bound, desorbing at room temperature, and strongly bound presumably as $\mathrm{NH}_{4}^{+}$(with $\mathrm{BAS}$ ), desorbing at elevated temperature, respectively. ${ }^{[18]}$ It is however, the resolution was unable to allow differentiation of the acidities of the BAS from $\mathrm{Zn}-\mathrm{AlPO}-$ 5 since the two peaks at the similar positions were observed (much smaller sizes of Zn-AlPO-5 indicated the smaller content of trapped ammonia). As a result, another independent method to evaluate acidity was also attempted. All catalysts were treated with trimethylphosphine oxide (TMPO) under a vacuum environment. The TMPO molecule, with lone pair electrons on the oxygen atom, is known to form an adduct with Brønsted acid protons. The acid strength of the BAS affects the adsorbed phosphorous electron density, such that solid state ${ }^{31} \mathrm{P}$ nuclear magnetic resonance (NMR) can be applied to quantify acid 
strength. In general, the stronger the acid strength of a BAS proton attached to the oxygen atom on TMPO, the greater the de-shielding of the phosphorous and the higher the chemical shift in the NMR spectrum. ${ }^{[19]}$ The ${ }^{31} \mathrm{P}$ chemical shift moves from 39 ppm (crystalline TMPO) towards a range of 50-105 ppm upon protonation of the oxygen of TMPO. The strength of BAS in zeolites can be generally classified according to the value of the ${ }^{31} \mathrm{P}$ chemical shift as very strong $(90-80 \mathrm{ppm})$, strong $(80-70 \mathrm{ppm})$, and weak $(70-60 \mathrm{ppm})$, where $86 \mathrm{ppm}$ is the calculated threshold of superacidity for TMPO. ${ }^{[2020]}$ As shown in Fig. S9, Zn-AlPO-5 shows a relative intense signal at $45 \mathrm{ppm}$ ( $c$ a. $42.2 \mu \mathrm{mol}$ weak BAS/g) on the spectrum whereas, a much smaller peak is observed over AlPO-5 ( $c a .11 .7 \mu \mathrm{mol}$ weak BAS/g) either a small impurity peak or a slightly acidic, terminal P-OH at $47 \mathrm{ppm}$ ). In contrast, a peak at 75-80 ppm (ca. $802.4 \mu \mathrm{mol}$ strong BAS/g) is observed in the spectrum of $\mathrm{Zn}$ ZSM-5 (Figure S9). Thus the chemical shift of TMPO due to BAS of Zn-ZSM-5 is considerable higher than that of the ZnAlPO-5. These results again clearly suggest that AlPO-5 does not possess BAS whereas the BAS of Zn-AlPO-5 is only weakly acidic. On the other hand, the acid strength of the BAS is much stronger in H-ZSM-5 based samples than that of $\mathrm{Zn}$ AlPO-5. Finally, it is worth noting that the 6-member ring cavity of Zn-AlPO-5 was too small for TMPO molecule to gain access such that there was only one BAS signal, from TMPO in the large pore of Zn-AlPO-5, observed by this technique.

The BAS characterisations by $\mathrm{NH}_{3}$-probe SXRD and TMPOprobe NMR clearly indicate that Zn-AlPO-5 gives much weaker BAS as compared to Zn-ZSM-5. We believe that the weak acidic strength can account for the ring opening of GVL to PA without inducing subsequent decarboxylation as reflected by the product distribution in Figure 1. The mechanism proposed for the formation of PA in substituted $\mathrm{Zn}$-AlPO-5 catalysts is shown in Scheme 1. The active species in the structure are thought to be a small amount of mild BAS created from the substitution of $\mathrm{Al}^{3+}$ by $\mathrm{Zn}^{2+}$ in the framework. It is envisaged that the reaction initiates with the protonation of the lactone group by this weak BAS, with subsequent attack by a water molecule and hydrolysis into the corresponding carboxylic acid. Finally, dehydration of the alcohol group leads to the formation of PA and its isomer (either 4-pentenoic aicd or 3-pentenoic acid). This mechanism is supported by the significant difference in conversion between Zn-AlPO-5 and AlPO-5 since aluminium substitution by zinc can generate a significant quantity of $\mathrm{BAS}$ as $\mathrm{Zn}-\mathrm{O}(\mathrm{H})-\mathrm{Al}$ in the structure. Moreover, this catalytic result cannot be obtained using stronger $\mathrm{Al}-\mathrm{O}\left(\mathrm{H}^{+}\right)-\mathrm{Si}$ sites in typical $\mathrm{SiO}_{2} / \mathrm{Al}_{2} \mathrm{O}_{3}$ or zeolitebased solid acid catalysts, where facile acid catalysed decarboxylation would continue to apply to the PA leading to formation of the butene molecule (Scheme S1).

We have further shown that an immobilised, extra-framework zinc in $\mathrm{Zn}-\mathrm{ZSM}-5$ gives a terminal $\mathrm{Zn}-\mathrm{OH}$. The incorporation of $\mathrm{Zn}$ in this structure can clearly catalyse the GVL conversion, giving higher activity and selectivity towards hydrocarbons/ aromatics (Figure 1). The acidity of $\mathrm{Zn}-\mathrm{OH}$ is anticipated to be weaker than that of the residual $\left(\mathrm{Al}-\mathrm{O}\left(\mathrm{H}^{+}\right)-\mathrm{Si}\right)$ BAS of $\mathrm{Zn}$ ZSM-5. However, this terminal group is known to be an excellent nucleophile due to its strong $(\mathrm{OH})^{\delta-}$. Here, we propose that it will have a synergetic effect with a BAS in close proximity inside the zeolite cavity, which leads to higher conversion of GVL and higher selectivity to hydrocarbons and aromatics products. This mechanism starts with a GVL molecule that is first protonated by a BAS. Subsequently, the lactone group of the GVL molecule is attacked by the terminal $\mathrm{Zn}-\mathrm{OH}$ group, which is a much stronger nucleophile than a water molecule. An initial PA intermediate may be formed but will be susceptible to further decarboxylation to butene and then BTX. As a result, stoichiometric hydrolysis and decarboxylation to hydrocarbons/ BTX and $\mathrm{CO}_{2}$ can be established in Scheme S2.

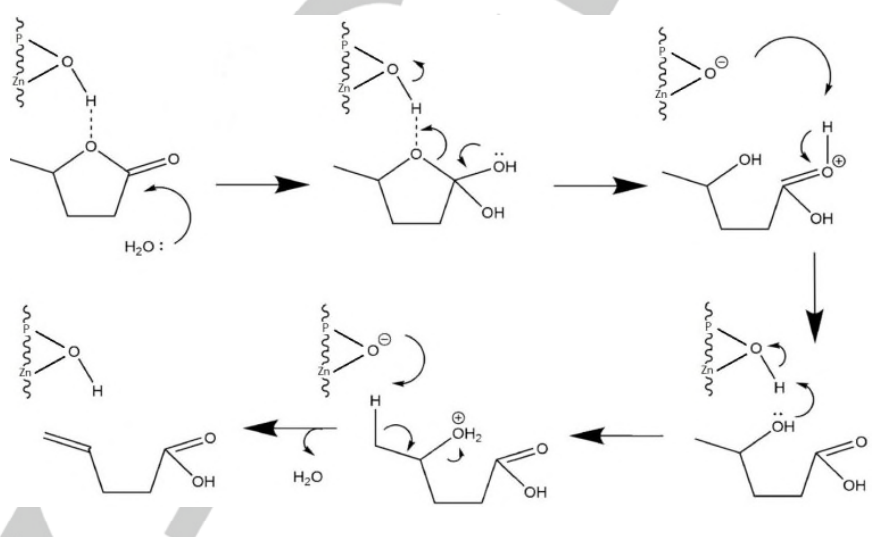

Scheme 1 The mechanism of PA formation from GVL catalyzed by weak BAS formed in Zn-AlPO-5. The wavy lines represent the zeolite wall. The final product although shown as 4-pentenoic acid in this mechanism but the other PA isomer, 3-pentenoic acid can also be formed.

In conclusion, the AlPO-5 structure with charge neutrality and absence of pores at long range structure shows to be chemically inert (give almost no activity) but when $\mathrm{Zn}^{2+}$ is incorporated, much higher GVL conversion can be obtained, suggesting the introduction of significant quantity of new weakly acid sites. From probe SXRD and probe-NMR, our results indicate that the $\mathrm{Zn}^{2+}$ species are in different chemical environment when they are placed into AIPO-5 instead of ZSM-5 using different synthesis methods. We therefore believe both the zeolite structures as well as the nature of zinc species and their interplays are important in this catalysis. The weak BAS established after the direct substitution $\mathrm{Zn}^{2+}$ into AlPO-5 facilitates for the first time, the hydrolysis of GVL to PA almost without catalysing the facile subsequent acid decarboxylation reaction. As a result, a new selective route for biomass conversion is hereby revealed. On the other hand, the characteristic terminal $\mathrm{Zn}-\mathrm{OH}$ in close proximity to the strong BAS that forms when $\mathrm{Zn}^{2+}$ is immobilised on H-ZSM-5 facilitates a cascade of ring-opening, hydrolysis, decarboxylation and aromatization reactions, which result in high yields of hydrocarbons/aromatics. It is also demonstrated from this work that using probe-SXRD and probe-NMR can guide the tuning of BAS acidity and chemical affinity (nucleophilicity) of single modifier atoms incorporated into crystalline microporous structures.

\section{Acknowledgements}

We thank Prof. Chiu Tang of Diamond Light Source, Ltd. UK (I11 beamline) for providing SXRD beamline for this work. Keywords: Zn-incorporated · AIPO . Gamma-valerolactone . mild hydrolysis · pentenoic acid 
[1] M. R. Rahimpour, M. Jafari, D. Iranshahi, Appl. Energ. 2013, 109, 79-93.

[2] G. W. Huber, S. Iborra, A. Corma, Chem. Rev. 2006, 106, 4044-4098.

[3] W. R. H. Wright, R. Palkovits, Chemsuschem 2012 5, 1657-1667.

[4] A. M. R. Galletti, C. Antonetti, V. De Luise, M. Martinelli, Green Chem. 2012, 14, 688-694.

[5] D. M. Alonso, S. G. Wettstein, J. A. Dumesic, Green Chem. 2013, 15, 584-595.

[6] I. T. Horvath, Green Chem. 2008, 10, 1024-1028.

[7] I. T. Horvath, H. Mehdi, V. Fabos, L. Boda, L. T. Mika, Green Chem. 2008, 10, 238-242.

[8] J. Q. Bond, D. M. Alonso, D. Wang, R. M. West, J. A. Dumesic, Science 2010, 327, 1110-1114.

[9] L. Ye, Q. Song, B. T. W. Lo, J. L. Zheng, D. J. Kong, C. A. Murray, C. C. Tang, S. C. E. Tsang, Angew. Chem. Int. Ed. 2017, 56, 10711-10716.

[10] L. Shirazi, E. Jamshidi, M. R. Ghasemi, Cryst. Res. Technol. 2008, 43, 1300-1306.

[11] S. T. Wilson, B. M. Lok, C. A. Messina, T. R. Cannan, E. M. Flanigen, J. Am. Chem. Soc. 1982, 104, 1146-1147.

[12] B. T. Qiao, A. Q. Wang, X. F. Yang, L. F. Allard, Z. Jiang, Y. T. Cui, J. Y. Liu, J. Li, T. Zhang, Nature Chem. 2011, 3, 634-641.

[13] X. F. Yang, A. Q. Wang, B. T. Qiao, J. Li, J. Y. Liu, T. Zhang, Acc. Chem. Res. 2013, 46, 17401748.
[14] M. Moliner, J. E. Gabay, C. E. Kliewer, R. T. Carr, J. Guzman, G. L. Casty, P. Serna, A. Corma, J. Am. Chem. Soc. 2016, 138, 15743-15750.

[15] Ruren Xu, Wenqin Pang, Jihong Yu, Qisheng Huo, J. Chen, Chemistry of Zeolites and Related Porous Materials: Synthesis and Structure, John Wiley and sons Ltd, Singapore, 2007.

[16] N. D. Browning, C. Aydin, J. Lu, A. Kulkarni, N. L. Okamoto, V. Ortalan, B. W. Reed, A. Uzun, B. C. Gates, ChemCatChem 2013, 5, 2673-2683.

[17] J. Lu, C. Aydin, N. D. Browning, B. C. Gates, Angew. Chem. Int. Ed. 2012, 51, 5842-5846.

[18] B. T. W. Lo, L. Ye, J. Qu, J. L. Sun, J. L. Zheng, D. J. Kong, C. A. Murray, C. C. Tang, S. C. E. Tsang, Angew. Chem. Int. Ed. 2016, 55, 5981-5984.

[19] L. Ye, B. T. W. Lo, J. Qu, I. Wilkinson, T. Hughes, C. A. Murray, C. C. Tang, S. C. E. Tsang, Chem. Commun. 2016, 52, 3422-3425.

[20] Y. Zhao, Y. Fu, Q. X. Guo, Bioresour Technol. 2012, 114, 740-744.

[21] L. Forni, F. P. Vatti, E. Ortoleva, Microporous Mater. 1995, 3, 367-375.

[22] Y. K. Peng, Y. C. Hu, H. L. Chou, Y. Y. Fu, I. F. Teixeira, L. Zhang, H. Y. He, S. C. E. Tsang, Nature Comm. 2017, 8, 675.

[23] C. E. Hernandez-Tamargo, A. Roldan, N. H. de Leeuw, J. Phys. Chem. C 2016, 120, 19097-19106.

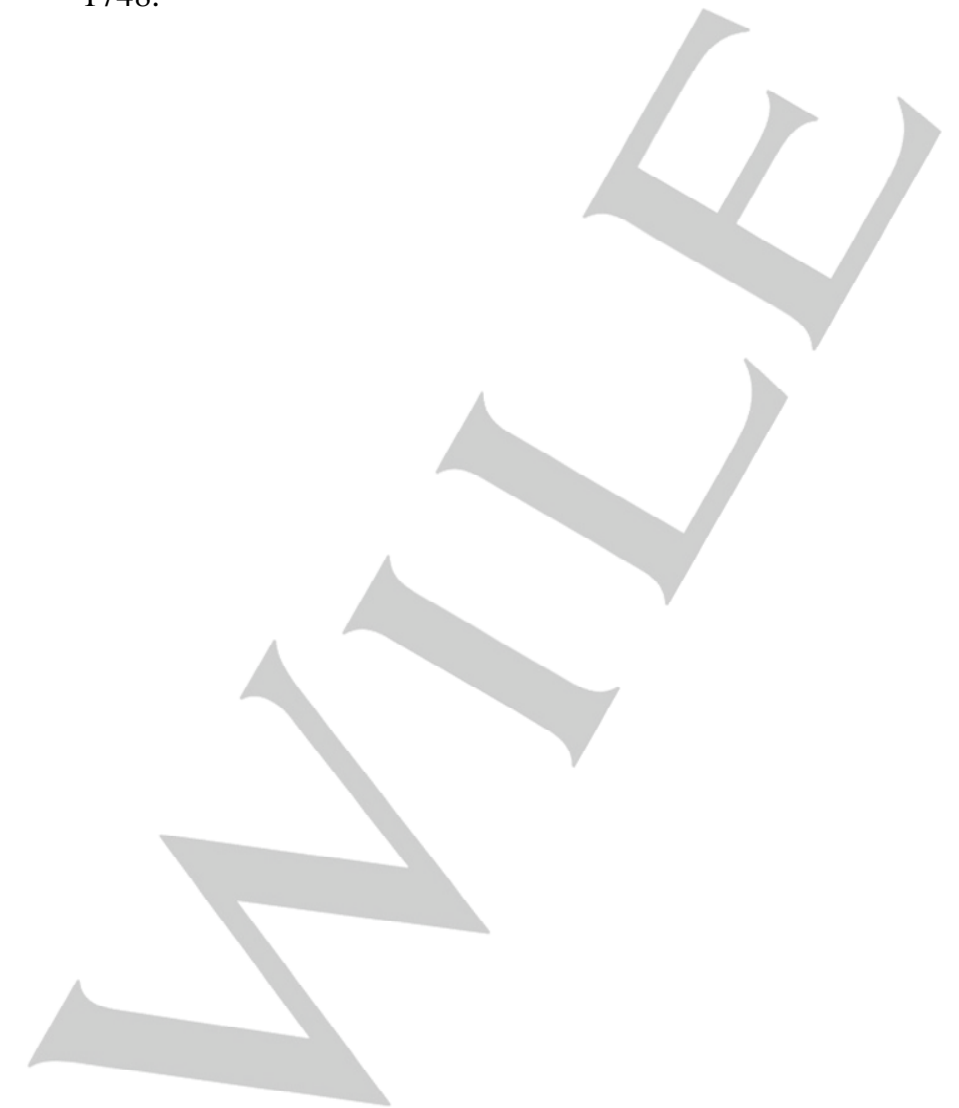




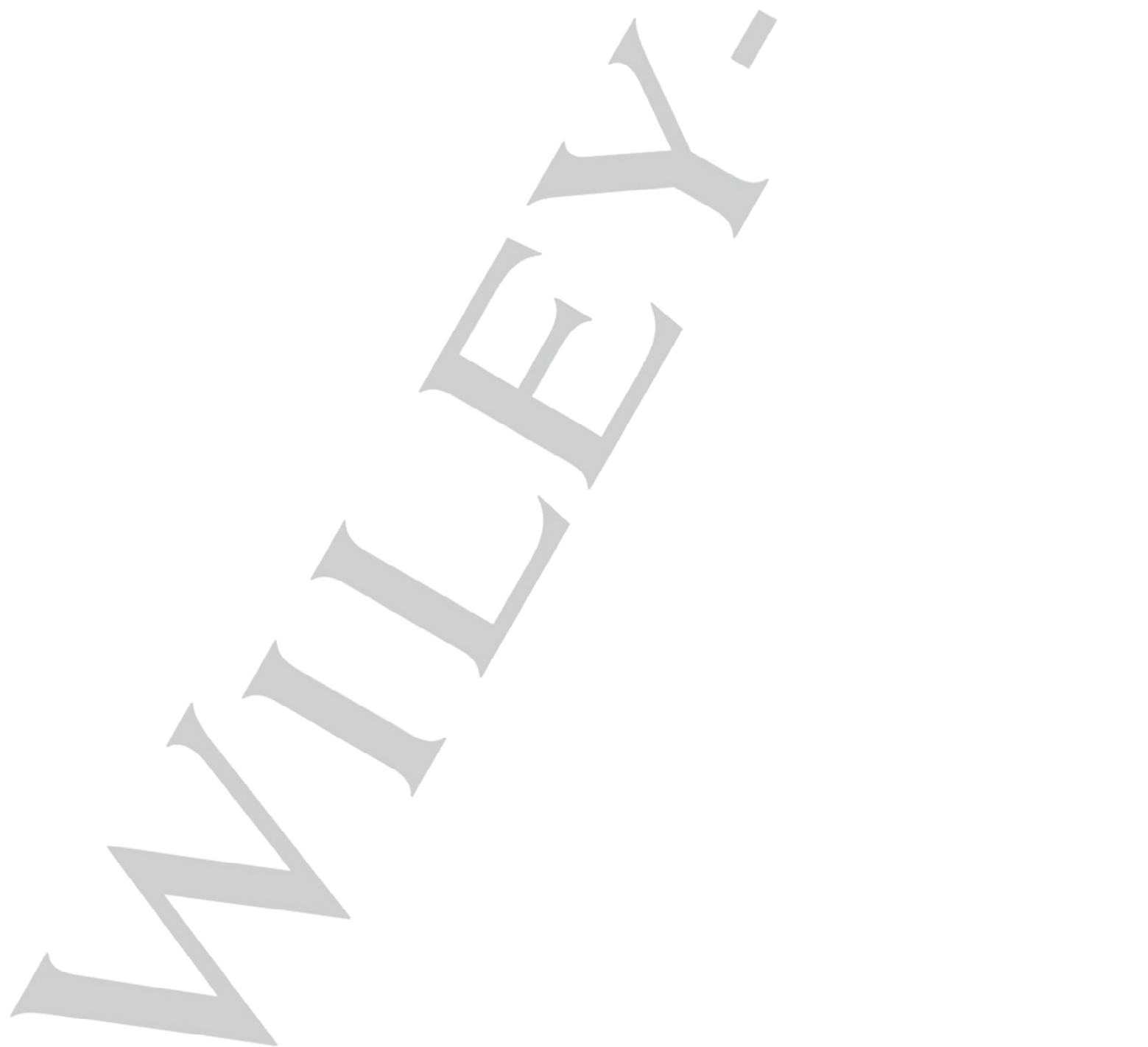

